\title{
Dietary L-arginine supplementation enhances intestinal development and expression of vascular endothelial growth factor in weanling piglets
}

\author{
Kang Yao ${ }^{1}$, Shu Guan ${ }^{2}$, Tiejun $\mathrm{Li}^{1}$, Ruilin Huang ${ }^{1}$, Guoyao Wu ${ }^{1,3,4}$, Zheng Ruan ${ }^{5 *}$ and Yulong Yin ${ }^{1 *}$ \\ ${ }^{1}$ Hunan Engineering and Research Center of Animal and Poultry Science, Key Laboratory for Agro-ecological Processes in \\ Subtropical Region, Institute of Subtropical Agriculture, Chinese Academy of Sciences, Hunan 410125, China \\ ${ }^{2}$ Guelph Food Research Centre Agriculture and Agri-Food Canada, 93 Stone Road West, Guelph, ON, Canada N1G 5C9 \\ ${ }^{3}$ Department of Animal Science, Texas AEM University, College Station, TX 77843-2471, USA \\ ${ }^{4}$ State Key Laboratory of Animal Nutrition, China Agricultural University, Beijing 100191, China \\ ${ }^{5}$ State Key Laboratory of Food Science and Technology and College of Life Science and Food Engineering, Nanchang \\ University, Jiangxi, Nanchang 330031, China
}

(Received 23 February 2010 - Revised 2 July 2010 - Accepted 5 July 2010 - First published online 10 January 2011)

\section{Abstract}

Oral administration of L-arginine has been reported to prevent gut disease in human infants. However, little is known about the effects of dietary arginine supplementation on intestinal development of weaned piglets. In the present study, twenty 21-d-old castrated piglets with 5.3 (SEM $0 \cdot 13$ ) kg body weight (BW) were weaned from sows, individually housed and randomly assigned to one of the two maize- and soyabean meal-based diets supplemented with 0 or $1 \%$ L-arginine. After consuming the diets for $7 \mathrm{~d}$, six pigs were randomly selected from each group to obtain various tissues. Compared with control pigs, dietary supplementation with $1 \%$ L-arginine did not affect feed intake but enhanced $(P<0.05)$ the relative weight of the small intestine $(+33 \%)$, daily BW gain $(+38 \%)$ and feed efficiency $(+28 \%)$. The villus height of the duodenum, jejunum and ileum in arginine-supplemented piglets was 21,28 and $25 \%$ greater $(P<0 \cdot 05)$ than in the nonsupplemented control group. Arginine supplementation increased $(P<0.05)$ protein levels for vascular endothelial growth factor (VEGF) in duodenal, jejunal and ileal mucosae by 14, 39 and 35\%, respectively. Compared with the control group, dietary supplementation with $1 \%$ L-arginine increased $(P<0.05)$ plasma concentrations of arginine and insulin $(+36 \%)$, and decreased $(P<0.05)$ plasma concentrations of cortisol $(-33 \%), \mathrm{NH}_{3}(-21 \%)$ and urea $(-19 \%)$. These results indicate that arginine supplementation enhances intestinal growth, development and expression of VEGF in early-weaned pigs fed a maize- and soyabean meal-based diet. The findings may have important implications for neonatal pigs under stressful or diseased conditions.

Key words: Arginine: Pigs: Growth: Intestine: Vascular endothelial growth factor

Arginine participates in multiple pathways with enormous nutritional and physiological importance, including the synthesis of protein, NO, creatine, proline, glutamate, polyamines and agmatine as well as the secretion of hormones $^{(1-6)}$. Increasing evidence shows that L-arginine is an essential amino acid for young mammals, particularly under conditions of severe stress ${ }^{(7,8)}$. For instance, our previous studies have shown that dietary supplementation with arginine, which is 50-95\% greater than National Research Council-recommended intake, stimulates muscle growth $^{(1,9)}$, enhances the immune status ${ }^{(5)}$ and improves microvascular development ${ }^{(10)}$ in neonatal pigs weaned at $7-21 \mathrm{~d}$ of age. Particularly, NO (a metabolite of
L-arginine) is a major vasodilator that regulates vascular tone and haemodynamics. Proline (another product of arginine catabolism) is a key component of extracellular matrix collagen that is crucial for angiogenesis and vascular remodelling ${ }^{(11,12)}$. Systemic administration of L-arginine has been proposed as a safe and effective method to enhance the synthesis of NO, proline and polyamines in animals, therefore improving wound healing and microcirculation $^{(13-15)}$.

Weaning stress is associated with reductions in food consumption, weight gain and growth, as well as increases in the incidence of diarrhoea and disease, intestinal dysfunction and atrophy, and deaths in piglets ${ }^{(16-22)}$. In response

Abbreviations: BW, body weight; VEGF, vascular endothelial growth factor.

*Corresponding author: Y. Yin, email yyulong2003@yahoo.com.cn; Z. Ruan, email ruanzheng@gmail.com 
to weaning, the digestive system of piglets must adapt to a dry diet, which is often based primarily on plant sources of ingredients (e.g. maize and soyabean meal) ${ }^{(23,24)}$. In the piglet small intestine, microvessels are present mainly in the mucosa and submucosa ${ }^{(25,26)}$, and the optimal development of villi depends on an adequate supply of nutrients from both blood via the intestinal microvessel and enteral feeding ${ }^{(27)}$. Changes in gut morphology may result in microvessel injury and disorders of microcirculation ${ }^{(28,29)}$. Microvascular endothelial dysfunction may be a major factor contributing to impaired absorption and transport of nutrients in animals ${ }^{(30)}$.

Of particular interest, weanling piglets have a particularly high requirement for dietary arginine ${ }^{(31)}$. Due to depressed feed intake in the first week post-weaning, low arginine intake may be one of the reasons for increased intestinal epithelial damage in early-weaned pigs. Adverse effects of an L-arginine deficiency may also include abnormal gene expression in the vasculature ${ }^{(10,11)}$. Therefore, we hypothesised that dietary L-arginine supplementation might prevent or alleviate intestinal atrophy and microcirculation disorder by increasing the expression of vascular endothelial growth factor (VEGF) in the small intestine of weanling pigs. The present study was conducted to test this hypothesis using 21- to 28-d-old piglets.

\section{Materials and methods}

\section{Animals and feeding}

We conducted the experiment in accordance with the Chinese guidelines for animal welfare, and it was approved by the Animal Welfare Committee of the Institute of Subtropical Agriculture, Chinese Academy of Sciences ${ }^{(32)}$.

Basal diets were formulated to meet National Research Council-recommended nutrient requirements for weanling piglets $^{(33)}$. Two diets were formulated by supplementing the basal diet with 0 and $1 \%$ L-arginine (free base). The diets were made isonitrogenous by the addition of L-alanine, as described by Kim \& Wu ${ }^{(34)}$.

A total of twenty large White $\times$ Landrace castrated piglets from five litters were weaned at $21 \mathrm{~d}$ of age (5.3 (SEM $0 \cdot 13) \mathrm{kg}$ ) and assigned randomly to one of the two treatment groups (ten pigs/group), representing dietary supplementation with $0.0 \%$ control or $1 \%$ L-arginine (Table 1). Piglets were individually housed in $1.3 \times 1.2 \mathrm{~m}$ pens with slotted stainless steel floors ${ }^{(35)}$. Each pen was equipped with a feeder and a nipple waterer. This facility allows pigs to have free access to feed and water. The room temperature was maintained at $25-27^{\circ} \mathrm{C}^{(36)}$. All the piglets were fed four times per day at 07.00, 11.00, 15.00 and 19.00 hours. The feed intake was measured daily. Fresh manure samples were collected daily for the determination of moisture. Samples with moisture content higher than $70 \%$ were considered
Table 1. Composition of the basal diet (as-fed basis)

\begin{tabular}{|c|c|}
\hline & Content (\%) \\
\hline \multicolumn{2}{|l|}{ Dietary ingredients } \\
\hline Maize & $50 \cdot 00$ \\
\hline Soyabean meal & $20 \cdot 00$ \\
\hline Whey & $10 \cdot 00$ \\
\hline Fish meal & 6.00 \\
\hline Soyabean oil & 2.50 \\
\hline Lactose & 2.50 \\
\hline Sucrose & $2 \cdot 00$ \\
\hline Glucose & $1 \cdot 80$ \\
\hline L-Lys.HCl & $1 \cdot 30$ \\
\hline Salt & 0.30 \\
\hline Limestone & 0.80 \\
\hline $\mathrm{CaHPO}_{4}$ & 1.80 \\
\hline Premix* & 1.00 \\
\hline \multicolumn{2}{|l|}{ Nutrient levels in the diet $†$} \\
\hline Digestible energy (MJ/kg) & 14.44 \\
\hline Crude protein (\%) & 23.50 \\
\hline Total Arg (\%) & $1 \cdot 14$ \\
\hline Total Lys (\%) & $1 \cdot 35$ \\
\hline Total Ca (\%) & 0.80 \\
\hline Total P (\%) & 0.65 \\
\hline \multicolumn{2}{|c|}{$\begin{array}{l}\text { * Supplied per kg diet: } \mathrm{Cu}, 10 \mathrm{mg} ; \mathrm{Fe}, 100 \mathrm{mg} ; \mathrm{Na}, 0.30 \mathrm{mg} ; \mathrm{Zn}, 100 \mathrm{mg} ; \mathrm{Mn} \text {, } \\
10 \mathrm{mg} \text {; cholecalciferol, } 386 \mathrm{IU} \text {; retinyl acetate, } 3086 \mathrm{IU} \text {; all-rac- } \alpha \text {-tocopheryl acet- } \\
\text { ate, } 15.4 \mathrm{IU} \text {; menadione, } 2.3 \mathrm{mg} \text {; riboflavin, } 3.9 \mathrm{mg} \text {; D-pantothenic acid, } 15.4 \mathrm{mg} \text {; } \\
\text { niacin, } 23 \mathrm{mg} \text {; choline, } 77 \mathrm{mg} \text {; cyanocobalamin, } 15.4 \mu \mathrm{g} \text {. } \\
\text { † Analysed values. }\end{array}$} \\
\hline
\end{tabular}

as diarrhoea. The incidence of diarrhoea for the piglets was calculated as ${ }^{(18)}$ :

Incidence of diarrhoea $=$

((number of piglets with diarrhoea

$\times$ number of days of diarrhoea)/(total number of piglets

$\times$ number of days of experiment)) $\times 100$.

\section{Sample collection}

Following a $7 \mathrm{~d}$ period of arginine supplementation, all piglets were weighed, and at $1 \mathrm{~h}$ after the last meal, jugular venous blood samples were obtained from heparinised tubes for the analysis of hormones and metabolites, whereas six pigs from each group were randomly selected and humanely killed by a lethal intraperitoneal injection of sodium pentobarbital ${ }^{(4)}$. Samples of duodenum, jejunum, ileum, liver, kidney, heart, spleen and lung were obtained immediately after the abdomen was opened ${ }^{(37)}$.

\section{Analysis of metabolites and hormones}

Amino acids in plasma were analysed using a HPLC method involving precolumn derivatisation with orthophthaldialdehyde ${ }^{(38)}$. L-Norvaline was used as an internal standard. An automated biochemistry analyzer (Synchron CX Pro; Beckman Coulter, Fullerton, CA, USA) was used to determine concentrations of urea, $\mathrm{NH}_{3}$, glucose, total protein and immune globulins in plasma, according to 
commercial kits and the manufacturer's instructions ${ }^{(39,40)}$. Cortisol, insulin, growth hormone, insulin-like growth factor-1, triiodothyronine and thyroxine in plasma were determined by RIA according to reagent kits and the manufacturer's instructions (China Institute of Atomic Energy, Beijing, China $)^{(41-43)}$.

\section{Histological analysis}

Intestinal tissue samples were fixed as described previously $^{(11)}$. Briefly, samples were placed in $10 \%$ neutral buffered formalin and embedded in paraffin for subsequent histological measurement. Six cross-sections were obtained from each formalin-fixed segment and processed for histological examination using the standard haematoxylin and eosin method ${ }^{(11)}$. Villus height and crypt depth were measured according to Wu et al. ${ }^{(44,45)}$. The histological analysis was performed by an investigator who was unaware of the origin of tissue sections.

\section{Immunohistochemistry}

Protein levels for VEGF were measured as described previously $^{(11)}$. Briefly, sections of formalin-fixed paraffin-embedded tissues were digested with $3 \% \mathrm{H}_{2} \mathrm{O}_{2}$ for $20 \mathrm{~min}$ at room temperature and incubated sequentially with $10 \%$ normal rabbit serum for $20 \mathrm{~min}$ after microwave antigen recovery, with VEGF (1:50) at $4{ }^{\circ} \mathrm{C}$ overnight and then with corresponding biotinylated secondary antibodies against rabbit and streptavidin peroxidase. Subsequently, binding of the primary antibody was detected with diaminobenzidine. Sections were counterstained with haematoxylin. In the negative control, the antibodies were substituted by PBS. Immunochemical staining sections were photographed using a Leica DFC 320 digital camera (Leica Microsystems, Cambridge, UK). The optical density for tissues was integrated by computer-assisted image analysis (Image-Pro Plus; Media Cybernetics, Bethesda, MD, USA) in each $400 \times$ magnified field $^{(46)}$. Eight microscopic fields for each section were quantified.

\section{Statistical analysis}

Results are expressed as means with pooled SEM. Data were analysed statistically using the General Linear Model procedure of the Statistical Analysis System (version 2000; SAS Institute, Cary, NC, USA) for one-way ANOVA. Differences between the groups were determined by the Student-Newman-Keuls multiple comparison test. Relationship between intestinal villus height and VEGF protein levels was evaluated by the Pearson correlation analysis (SAS Institute). Probability values $\leq 0.05$ were taken to indicate statistical significance.
Table 2. Effects of dietary L-arginine supplementation for $7 d$ on the growth performance and diarrhoea incidence of weaned pigs

(Mean values with their pooled standard errors, $n$ 10)

\begin{tabular}{lccc}
\hline Variable & Control & $1 \%$ Arg & Pooled SEM \\
\hline Initial body wt $(\mathrm{kg})$ & $5 \cdot 27$ & 5.33 & 0.11 \\
Final body wt $(\mathrm{kg})$ & $6 \cdot 17^{\mathrm{a}}$ & $6.72^{\mathrm{b}}$ & 0.19 \\
ADG $(\mathrm{g})$ & $120^{\mathrm{a}}$ & $187^{\mathrm{b}}$ & $2 \cdot 6$ \\
ADFI (g/d) & 183 & 187 & 13 \\
Feed:gain ratio & $1.56^{\mathrm{a}}$ & $1.12^{\mathrm{b}}$ & 0.03 \\
Diarrhoea incidence (\%) & 3.8 & 3.2 & 0.52 \\
\hline
\end{tabular}

ADG, average daily gain; ADFI, average daily feed intake.

${ }^{a, b}$ Mean values within a row with unlike superscript letters were significantly different $(P<0.05)$.

\section{Results}

\section{Feed intake and growth performance}

Daily food intake did not differ between control and arginine-supplemented piglets during a $7 \mathrm{~d}$ experimental period (Table 2). The initial body weight (BW) at $21 \mathrm{~d}$ of age did not differ between the two groups (Table 2). However, compared with the control group, dietary supplementation with L-arginine increased $(P<0.05)$ the final BW by $9 \%$ and enhanced daily weight gain of piglets by $56 \%$, respectively. Moreover, 1\% L-arginine supplementation decreased $(P<0.05)$ the ratio of DM intake:BW gain $(\mathrm{g} / \mathrm{g}$; an indicator of feed efficiency) by $28 \%$. Diarrhoea incidence did not differ between the control and arginine-supplemented groups.

\section{Plasma amino acids}

Dietary supplementation with $1 \%$ L-arginine increased $(P<0.05)$ plasma concentrations of arginine and ornithine by 33 and $30 \%$, respectively, but had no effect on plasma concentrations of citrulline or lysine (Table 3).

Table 3. Effects of dietary L-arginine supplementation for $7 \mathrm{~d}$ on plasma metabolites and hormones in weaned piglets

(Mean values with their pooled standard errors, $n 6$ )

\begin{tabular}{|c|c|c|c|}
\hline Variable & Control & $1 \%$ Arg & Pooled SEM \\
\hline $\operatorname{Arg}(\mu \mathrm{mol} / \mathrm{l})$ & $284^{a}$ & $377^{\mathrm{b}}$ & 13 \\
\hline Ornithine $(\mu \mathrm{mol} / \mathrm{l})$ & $102^{a}$ & $133^{b}$ & 5.9 \\
\hline Citrulline $(\mu \mathrm{mol} / \mathrm{l})$ & $65 \cdot 3$ & $70 \cdot 8$ & 6.5 \\
\hline Lys $(\mu \mathrm{mol} / \mathrm{l})$ & 407 & 373 & $32 \cdot 3$ \\
\hline Urea (mmol/l) & $3 \cdot 19^{a}$ & $2 \cdot 60^{b}$ & 0.53 \\
\hline $\mathrm{NH}_{3}(\mu \mathrm{mol} / \mathrm{l})$ & $86 \cdot 7^{\mathrm{a}}$ & $71 \cdot 6^{b}$ & $3 \cdot 1$ \\
\hline Glucose (mmol/l) & $8 \cdot 46$ & $8 \cdot 30$ & 0.79 \\
\hline Total protein $(\mathrm{g} / \mathrm{l})$ & $49 \cdot 7$ & $52 \cdot 4$ & $3 \cdot 2$ \\
\hline Total albumin (g/l) & $27 \cdot 5$ & $29 \cdot 1$ & $2 \cdot 0$ \\
\hline Cortisol $(\mu \mathrm{g} / \mathrm{l})$ & $132^{a}$ & $88 \cdot 7^{b}$ & $8 \cdot 1$ \\
\hline Insulin (U/ml) & $14 \cdot 2^{a}$ & $18 \cdot 1^{b}$ & $1 \cdot 2$ \\
\hline $\mathrm{GH}(\mathrm{U} / \mathrm{ml})$ & 0.14 & 0.19 & 0.05 \\
\hline IGF-1 $(\mu \mathrm{g} / \mathrm{l})$ & 246 & 257 & $7 \cdot 3$ \\
\hline T3 $(\mu \mathrm{g} / \mathrm{l})$ & 0.84 & $1 \cdot 14$ & 0.16 \\
\hline $\mathrm{T} 4(\mu \mathrm{g} / \mathrm{l})$ & 71.7 & 78.9 & 10 \\
\hline
\end{tabular}

GH, growth hormone; IGF-1, insulin-like growth factor-1; T3, triiodothyronine; T4, thyroxine.

${ }^{a, b}$ Mean values within a row with unlike superscript letters were significantly different $(P<0.05)$. 
Plasma concentrations of histidine, asparagine, aspartate, isoleucine, leucine, methionine, phenylalanine, serine, taurine, threonine, tryptophan, tyrosine or valine did not differ between the control and arginine-supplemented groups (data not shown).

\section{Plasma urea, ammonia and hormones}

Dietary supplementation with $1 \%$ L-arginine decreased $(P<0.05)$ plasma concentrations of $\mathrm{NH}_{3}$ and urea by 17 and $18 \%$, respectively (Table 3 ). Plasma concentrations of glucose, total protein and total albumin were not affected by L-arginine supplementation (Table 3). Compared with control pigs, dietary supplementation with $1 \%$ L-arginine increased $(P<0.05)$ plasma concentrations of insulin by $27 \%$ and decreased $(P<0.05)$ plasma concentrations of cortisol by 33\% (Table 3 ). Dietary supplementation with $1 \%$ L-arginine did not affect plasma concentrations of growth hormone, insulin-like growth factor-1, triiodothyronine or thyroxine (Table 3).

\section{Relative weight of internal organs}

The relative weights $(\mathrm{g} / \mathrm{kg} \mathrm{BW})$ of kidney, heart, spleen and lung were not affected by L-arginine supplementation (data not shown). The relative weight of the small intestine was 33\% heavier $(P<0.05)$ in arginine-supplemented pigs compared with that of the control group $(73 \cdot 1 v .54 .9 \mathrm{~g} / \mathrm{kg}$ $\mathrm{BW}$, pooled $\mathrm{sEM}=4.4 \mathrm{~g} / \mathrm{kg} \mathrm{BW})$.
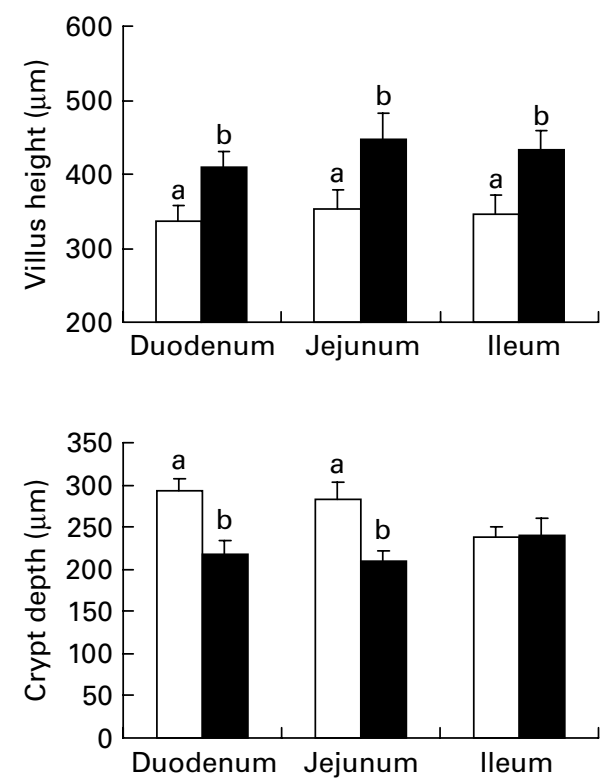

Fig. 1. Effects of dietary L-arginine supplementation for $7 d$ on the morphology of the small intestine in early-weaned piglets. Values are means with pooled SEM $(n 6)$. ${ }^{\mathrm{a}, \mathrm{b}}$ Mean values with unlike letters were significantly different $(P<0.05)$. $\mathbf{\square}$, Control; $\square, 1 \%$ L-arginine.

\section{Small-intestinal morphology and vascular endothelial} growth factor immunoreactive expression

To determine the effect of L-arginine supplementation on intestinal development, the piglet small intestine was collected at the end of the experiment, and the villus height and crypt depth were examined (Fig. 1). Supplementation with $1 \%$ L-arginine increased $(P<0.05)$ the villus height throughout the small intestine, compared with the control group. Crypt depth was greater $(P<0.05)$ in the duodenum and jejunum of the control group than that of the argininesupplemented pigs.

The immunoreactive VEGF protein was readily detected in the piglet small intestine (Fig. 2). Quantitatively, dietary supplementation with $1 \%$ L-arginine increased $(P<0.05)$ the integrated optical density in the duodenal submucosa, middle jejunal mucosa and submucosa, and the ileal mucosa by 14,39 and 54\%, respectively (Table 4 and Fig. 2). Correlation coefficients $\left(R^{2}\right)$ between villus height and VEGF protein intensity were 0.954, 0.958 and 0.956 $(P<0 \cdot 01)$, respectively, for the duodenum, jejunum and ileum.

\section{Discussion}

Intestinal development of the piglet was greatly suppressed in the first week after weaning in association with intestinal dysfunction and atrophy ${ }^{(22)}$, which is the major cause of reductions in nutrient absorption and utilisation as well

(a)
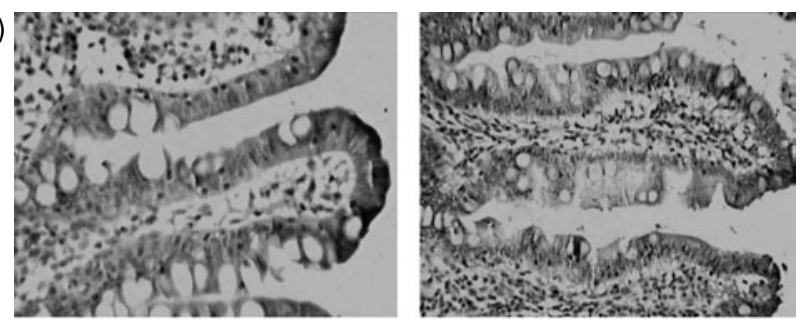

(b)

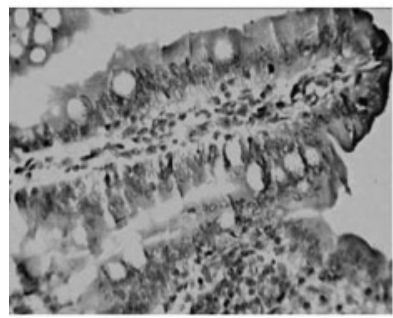

(c)

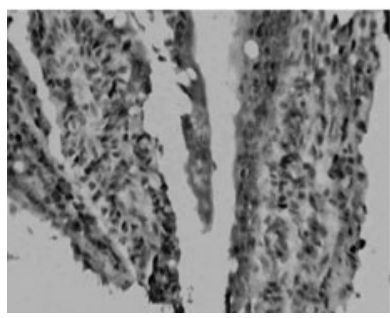

Control

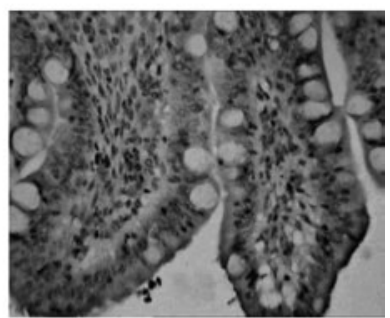

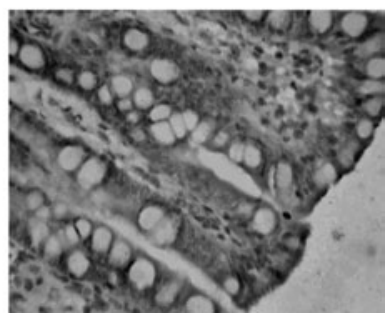

$1 \%$ L-Arginine
Fig. 2. Immunostaining of the vascular endothelial growth factor protein in the duodenum (a), jejunum (b) and ileum (c) of early-weaned piglets. 
Table 4. Effects of dietary L-arginine supplementation for $7 \mathrm{~d}$ on vascular endothelial growth factor protein levels in the small intestine of weaned piglets

(Mean values (arbitrary unit) with their pooled standard errors, $n 6$ )

\begin{tabular}{lccc}
\hline Intestine & Control & $1 \%$ L-Arg & Pooled SEM \\
\hline Duodenum & $981^{\mathrm{a}}$ & $1121^{\mathrm{b}}$ & 53 \\
Jejunum & $893^{\mathrm{a}}$ & $1244^{\mathrm{b}}$ & 76 \\
lleum & $715^{\mathrm{a}}$ & $1098^{\mathrm{b}}$ & 85 \\
\hline
\end{tabular}

${ }^{a, b}$ Mean values within a row with unlike superscript letters were significantly different $(P<0.05)$

as increases in diarrhoea and deaths. Available evidence shows that VEGF enhances intestinal vascular development, endothelial function and epithelial cell migration while inhibiting endothelin-1 release as well as platelet aggregation and adhesion ${ }^{(4-50)}$. Results of the present study indicated that dietary supplementation with $1 \%$ L-arginine had a positive effect on increasing villus height (Fig. 1) and the expression of the VEGF protein (Table 4 and Fig. 2). Notably, increases in both relative weight and villus height of the small intestine were positively correlated with the augmented expression of VEGF (see the Results section). The findings indicate that dietary supplementation with $1 \%$ arginine can improve the vascular development of the small intestine in weanling pigs by stimulating VEGF expression.

Elevated levels of cortisol in plasma are considered to be biomarkers for weaning stress ${ }^{(34)}$. Interestingly, in the present study, we found that dietary supplementation with $1 \%$ L-arginine decreased the circulating level of cortisol, but underlying mechanisms are unknown. Cortisol is the major glucocorticoid in pigs ${ }^{(51)}$. It is synthesised in the adrenal cortex and released into the circulation in response to external and internal factors acting on the hypothalamus and pituitary glands ${ }^{(52)}$. It is possible that NO or L-arginine itself attenuates the release of the adrenocorticotropic hormone from corticotroph cells and/or interferes with adrenocorticotropic hormone's actions on the adrenal cortex via specific receptors (e.g. type 2 melanocortin receptors). Further research is warranted to test this novel hypothesis.

Arginine plays important roles in both growth and metabolic function in piglets ${ }^{(53)}$. In rodents and human subjects, L-arginine is a nutritionally essential amino acid under conditions associated with increased utilisation relative to endogenous synthesis, including growth, inflammation and tissue repair ${ }^{(44)}$. In such cases, dietary supply can become rate limiting for the arginine-metabolising pathways $^{(54)}$. As previously reported ${ }^{(39)}$, arginine is deficient in weanling piglets (Table 3). Interestingly, intestinal synthesis of citrulline and arginine from glutamine and glutamate decreases by $70-73 \%$ in 7 -d-old suckling pigs in comparison with newborn pigs and declines further in 14- to 21-d-old pigs ${ }^{(55)}$. Thus, dietary supplementation with 0.2 and $0 \cdot 4 \%$ arginine to 7 - to 21 -d-old pigs (artificially reared on a milk feeding system) dose dependently enhanced plasma arginine concentrations (30 and 61\%) and reduced plasma $\mathrm{NH}_{3}$ levels (20 and 35\%) ${ }^{(56)}$.

Insulin is a major regulatory hormone in glucose and fat metabolism, vascular function, inflammation, tissue remodelling and the somatotropic axis of growth ${ }^{(40,41)}$. Arginine is a potent stimulator of the secretion of insulin by pancreatic $\beta$-cells and of growth hormone by the anterior pituitary gland in mammals ${ }^{(45)}$, including young pigs ${ }^{(46)}$. This is consistent with our finding that dietary supplementation with $1 \% \mathrm{~L}$-arginine increased plasma levels of insulin. Through an increase in arginine availability and the concurrent increases in plasma concentrations of anabolic hormones (Table 3), dietary arginine supplementation improved the efficiency of nutrient utilisation for enhancing tissue protein synthesis and growth performance. In support of this view, plasma concentrations of urea (the major nitrogenous product of protein and amino acid catabolism) were markedly reduced in arginine-supplemented pigs compared with control pigs (Table 3). Growth hormone is another important hormone in growth regulation, which plays a role in the secretion of thyroid hormone (mainly produced in the liver). However, L-arginine supplementation did not affect circulating levels of growth hormone or thyroid hormones (Table 3).

In keeping with the previous report ${ }^{(11)}$, dietary supplementation with $1 \%$ arginine markedly enhanced daily weight gain in weaning piglets (Table 2), indicating that arginine deficiency is a major factor limiting their maximum growth performance. It is noteworthy that experimental conditions differed greatly between the present study and the work of Zhan et $a l .{ }^{(10)}$. For instance, the initial age $(21 \mathrm{~d})$ and initial mean BW $(5.3 \mathrm{~kg})$ of piglets in the present study were greater than those of the piglets used by Zhan et al. ( $14 \mathrm{~d}$ and $5.0 \mathrm{~kg}$, respectively). Additionally, food intake of piglets was lower in the Zhan et al.'s experiment ( $140 \mathrm{~g} / \mathrm{d})$ compared with the present one $(185 \mathrm{~g} / \mathrm{d})$ (Table 2$)$. Furthermore, the doses of supplemental arginine (0.7 v. 1\%) differed between the two investigations. Regardless of the low feed intake, $0.7 \%$ arginine supplementation may not be sufficient to meet the requirement of weanling piglets for maximal growth, whereas $1.2 \%$ arginine supplementation caused severe diarrhoea ${ }^{(11)}$. Clearly, proper supplementation of arginine is critical for experiment design.

Another significant finding from the present study is that dietary supplementation with $1 \%$ L-arginine increased the weight of the small intestine (see the Results section), which is consistent with the observation that arginine can increase protein synthesis ${ }^{(57)}$, inhibit protein degradation and enhance the proliferation of intestinal epithelial cells ${ }^{(58)}$. It is now known that arginine activates the mammalian target of rapamycin signalling in the intestine ${ }^{(59)}$, therefore promoting the initiation of polypeptide formation. These findings provide a molecular basis for our observation that L-arginine supplementation can improve the feed efficiency and growth performance of weanling 
piglets. Because preterm infants are deficient in arginine and exhibit intestinal dysfunction ${ }^{(48)}$, the present results may have important implications for managing this compromised population of neonates.

In conclusion, dietary supplementation with $1 \%$ L-arginine stimulates intestinal VEGF expression and development in weanling piglets, thereby contributing to improved vascular function and growth performance. Adequate provision of L-arginine in the weanling diet may be an effective means of ameliorating microvessel injury and enhancing the absorption of nutrients in the small intestine.

\section{Acknowledgements}

The present research was jointly supported by grants from the Chinese Academy of Sciences and Knowledge Innovation Project (Kscx2-Yw-N-051 and Y022042020) National 863 Program of China (2008AA10Z316), Research Program of State Key Laboratory of Food Science and Technology, Nanchang University (project no. SKLF-TS-200817), National Basic Research Program of China (2009CB118806), NSFC (30901040, 30901041, 30928018, 30828025 and 30771558), National Scientific and Technological Supporting Project (2006BAD12B02-5-2 and 2006BAD12B02-5-2), the Program for Ganjiang Scholars and Innovative Research Team in Nanchang University (IRT0540), the CAS/SAFEA International Partnership Program for Creative Research Teams, the Thousand-People-Talent program at China Agricultural University, National Research Initiative Competitive Grants from the Animal Growth \& Nutrient Utilization Program (2008-35206-18764) of the USDA National Institute of Food and Agriculture and Texas AgriLife Research (H-8200). The authors have no conflicts of interest to declare. Y. Y. was in charge of the whole project. K. Y. conducted the animal trial and wrote the paper. S. G., T. L., R. H. and Z. R. assisted with tissue collection and chemical analyses. G. W. helped to design the experiment, interpret the data and write the paper.

\section{References}

1. Yao K, Yin YL, Chu WY, et al. (2008) Dietary arginine supplementation increases mTOR signaling activity in skeletal muscle of neonatal pigs. J Nutr 138, 867-872.

2. Li P, Yin YL, Li DF, et al. (2007) Amino acids and immune function. Br J Nutr 98, 237-252.

3. Tan BE, Yin YL, Liu ZQ, et al. (2009) Dietary L-arginine supplementation increases muscle gain and reduces body fat mass in growing-finishing pigs. Amino Acids 37, 169-175.

4. He QH, Kong XF, Wu GY, et al. (2009) Metabolomic analysis of the response of growing pigs to dietary L-arginine supplementation. Amino Acids 37, 199-208.

5. Tan BE, Li XL, Kong XF, et al. (2009) Dietary L-arginine supplementation enhances the immune status in early-weaned piglets. Amino Acids 37, 323-331.

6. Tan BE, Yin YL, Liu ZQ, et al. (2010) Dietary L-arginine supplementation differentially regulates expression of fat-metabolic genes in porcine adipose tissue and skeletal muscle. J Nutr Biochem (Epublication ahead of print version 7 July 2010).

7. Wakabayashi Y, Yamada E, Yoshida T, et al. (1994) Arginine becomes an essential amino acid after massive resection of rat small intestine. J Biol Chem 269, 32667-32671.

8. Wu X, Ruan Z, Gao Y, et al. (2010) Dietary supplementation with L-arginine or $\mathrm{N}$-carbamylglutamate enhances intestinal growth and heat shock protein-70 expression in weanling pigs fed a corn- and soybean meal-based diet. Amino Acids 39, 831-839.

9. Frank JW, Escobar J, Hguyen HV, et al. (2007) Oral $N$-carbamylglutamate supplementation increases protein synthesis in skeletal muscle of piglets. J Nutr 137, 315-319.

10. Zhan ZF, Ou DY, Piao XS, et al. (2008) Dietary arginine supplementation affects microvascular development in the small intestine of early-weaned pigs. J Nutr 138, 1304-1309.

11. Mussini E, Hutton J Jr \& Udenfriend S (1967) Collagen proline hydroxylase in wound healing, granuloma formation, scurvy, and growth. Science 157, 927-929.

12. Adams E \& Frank L (1980) Metabolism of proline and the hydroxyprolines. Annu Rev Biochem 49, 1005-1061.

13. Wu GY \& Meininger CJ (2000) Arginine nutrition and cardiovascular function. J Nutr 130, 2626-2629.

14. Wu G, Bazer FW, Cudd TA, et al. (2007) Pharmacokinetics and safety of arginine supplementation in animals. $J$ Nutr 137, S1673-S1680.

15. Barbul A, Lazarou SA, Efron DT, et al. (1990) Arginine enhances wound healing and lymphocyte immune responses in humans. Surgery 108, 331-336.

16. Yuan DZ, Zhang JW, Wu GY, et al. (2007) Dietary supplementation with polysaccharides from Semen cassiae enhances immunoglobulin production and interleukin gene expression in early-weaned piglets. J Sci Food Agric 87, 1868-1873.

17. Deng D, Yao K, Chu WY, et al. (2009) Impaired translation initiation activation and reduced protein synthesis in weaned piglets fed a low-protein diet. J Biol Chem 20, $544-552$.

18. Hampson DJ (1986) Alterations in piglet small intestinal structure at weaning. Res Vet Sci 40, 32-40.

19. Wu G (2009) Amino acids: metabolism, functions, and nutrition. Amino Acids 37, 1-17.

20. Boudry G, Peron V, Le Huerou-Luron I, et al. (2004) Weaning induces both transient and long-lasting modifications of absorptive, secretory, and barrier properties of piglet intestine. J Nutr 134, 2256-2262.

21. Castillo M, Martin-Orue SM, Nofrarias M, et al. (2007) Changes in caecal microbiota and mucosal morphology of weaned pigs. Vet Microbiol 124, 239-247.

22. Lalles JP, Bosi P, Smidt H, et al. (2007) Weaning - a challenge to gut physiologists. Livest Sci 108, 82-93.

23. Kelly D, Smyth JA \& McCracken KJ (1991) Digestive development of the earlyweaned pig. 1. Effect of continuous nutrient supply on the development of the digestive tract and on changes in digestive enzyme activity during the first week post-weaning. BrJ Nutr 65, 169-180.

24. Ou DY, Li DF, Cao YH, et al. (2007) Dietary supplementation with zinc oxide decreases expression of the stem cell factor in the small intestine of weanling pigs. J Nutr Biochem 18, $820-826$.

25. Gore RW \& Bohlen HG (1977) Microvascular pressures in rat intestinal muscle and mucosal villi. Am J Physiol Heart Circ Physiol 233, 685-693.

26. Sieber C, Beglinger C, Jaeger K, et al. (1991) Regulation of postprandial mesenteric blood flow in humans: evidence for a cholinergic nervous reflex. Gut 32, 361-366. 
27. Matheson PJ, Wilson MA \& Garrison RN (2000) Regulation of intestinal blood flow. J Surg Res 93, 182-196.

28. Kalia N, Pockley AG, Wood RFM, et al. (2001) Effects of FK409 on intestinal ischemia-reperfusion injury and ischemia-induced changes in the rat mucosal villus microcirculation. Transplantation 72, 1875-1880.

29. Nakajima Y, Baudry N, Duranteau J, et al. (2001) Microcirculation in intestinal villi: a comparison between hemorrhagic and endotoxin shock. Am J Respir Crit Care Med 164, 1526-1530.

30. Granger DN \& Kubes P (1994) The microcirculation and inflammation: modulation of leukocyte-endothelial cell adhesion. J Leukoc Biol 55, 662-675.

31. Wu G, Knabe DA \& Kim SW (2004) Arginine nutrition in neonatal pigs. J Nutr 134, 2783S-2790S.

32. Tang ZR, Yin YL, Zhang YM, et al. (2009) Effects of dietary supplementation with an expressed fusion peptide bovine lactoferricin-lactoferrampin on performance, immune function and intestinal mucosal morphology in piglets weaned at age $21 \mathrm{~d}$. Br J Nutr 101, 998-1005.

33. National Research Council (NRC) (1998) Nutrient Requirements of Swine. Washington, DC: National Academy Press.

34. Kim SW \& Wu G (2004) Dietary arginine supplementation enhances the growth of milk-fed young pigs. J Nutr 134, 625-630.

35. Kang P, Yin YL, Ruan Z, et al. (2008) Effect of replacement of lactose with partially hydrolysed rice syrup on small intestine development in weaned pigs from 7 to 21 days. J Sci Food Agric 88, 1932-1938.

36. Yin YL, Li TJ \& Huang RL (2008) Evaluating standardized ileal digestibility of amino acids in growing pigs. Anim Feed Sci Tech 140, 385-401.

37. Wang JJ, Chen LX, Li P, et al. (2008) Gene expression is altered in piglet small intestine by weaning and dietary glutamine supplementation. J Nutr 138, 1025-1032.

38. Yin FG, Liu YL, Yin YL, et al. (2009) Dietary supplementation with Astragalus polysaccharide enhances ileal digestibilities and serum concentrations of amino acids in early weaned piglets. Amino Acids 37, 263-270.

39. Li LL, Wu X, Peng HZ, et al. (2009) The effect of dietary addition of a polysaccharide from atractylodes macrophala koidz on growth performance, immunoglobulin concentration and IL-1 $\beta$ expression in weaned pigs. J Agric Sci 147, 625-631.

40. Kong XF, Yin FG, He QH, et al. (2009) Acanthopanax senticosus extract as a dietary additive enhances the apparent ileal digestibility of amino acids in weaned piglets. Livest Sci 123, 261-267.

41. Deng D, Wu X, Bin S, et al. (2010) Dietary amylose and amylopectin ratio and resistant starch content affects plasma glucose, lactic acid, hormone levels and protein synthesis in splanchnic tissues. J Anim Physiol Anim Nutr 94, 220-226.

42. Kong XF, Yin YL, He QH, et al. (2008) Dietary supplementation with Chinese herbal powder enhances ileal digestibilities and serum concentrations of amino acids in young pigs. Amino Acids 37, 573-582.

43. Kong XF, Wu GY, Liao YP, et al. (2007) Effects of Chinese herbal ultra-fine powder as a dietary additive on growth performance, serum metabolites and intestinal health in early-weaned piglets. Livest Sci 108, 272-275.

44. Wu G, Bazer FW, Davis TA, et al. (2009) Arginine metabolism and nutrition in growth, health and disease. Amino Acids 37, 153-168.

45. Wu G, Meier SA \& Knabe DA (1996) Dietary glutamine supplementation prevents jejunal atrophy in weaned pigs. J Nutr 126, 2578-2584.

46. Zhou X, Li D, Yin J, et al. (2007) CLA differently regulates adipogenesis in stromal vascular cells from porcine subcutaneous adipose and skeletal muscle. J Lipid Res $\mathbf{4 8}$, 1701-1709.

47. Rhoads JM, Chen W, Gookin J, et al. (2004) Arginine stimulates intestinal cell migration through a focal adhesion kinase dependent mechanism. Gut 53, 514-522.

48. Ziche M, Morbidelli L, Choudhuri R, et al. (1997) Nitric oxide synthase lies downstream from vascular endothelial growth factor-induced but not basic fibroblast growth factor-induced angiogenesis. J Clin Invest 99, 2625-2634.

49. Lee PC, Salyapongse AN, Bragdon GA, et al. (1999) Impaired wound healing and angiogenesis in eNOS-deficient mice. Am J Physiol Heart Circ Physiol 277, 1600-1608.

50. Cao R, Eriksson A, Kubo H, et al. (2004) Comparative evaluation of FGF-2-, VEGF-A-, and VEGF-C-induced angiogenesis, lymphangiogenesis, vascular fenestrations, and permeability. Circ Res 94, 664-670.

51. Breinekova K, Svoboda M, Smutna M, et al. (2007) Markers of acute stress in pigs. Physiol Res 56, 323-329.

52. Flynn NE, Bird JG \& Guthrie AS (2009) Glucocorticoid regulation of amino acid and polyamine metabolism in the small intestine. Amino Acids 37, 123-129.

53. Papadimitriou A \& Priftis KN (2009) Regulation of the hypothalamic-pituitary-adrenal axis. Neuroimmunomodulation 16, 265-271.

54. Wu GY, Knabe DA \& Flynn NE (1994) Synthesis of citrulline from glutamine in pig enterocytes. Biochem J 299, 115-121.

55. Wu G, Bazer FW, Davis TA, et al. (2009) Arginine metabolism and nutrition in growth, health and disease. Amino Acids 37 , 153-168.

56. Leibholz J (1982) Arginine requirements of pigs between 7 and 28 days of age. Aust J Agric Res 33, 165-170.

57. Jobgen WS, Fried SK, Fu WJ, et al. (2006) Regulatory role for the arginine-nitric oxide pathway in metabolism of energy substrates. J Nutr Biochem 17, 571-588.

58. Benjamin AC, Odle J, Niu XM, et al. (2008) Arginine activates intestinal $\mathrm{p} 70(\mathrm{~S} 6 \mathrm{k})$ and protein synthesis in piglet rotavirus enteritis. J Nutr 138, 24-29.

59. Rhoads JM \& Wu G (2009) Glutamine, arginine, and leucine signaling in the intestine. Amino Acids 37, 111-122. 